\title{
KAJIAN PEMBERIAN PUPUK P, PUPUK MIKRO DAN PUPUK ORGANIK TERHADAP SERAPAN P DAN HASIL KEDELAI (Glycine max L.) VARIETAS KABA DI INSEPTISOL GUNUNG GAJAH KLATEN
}

\author{
Supriyadi, Sri Hartati, Almar Aminudin \\ Program Studi Ilmu Tanah, Fakultas Pertanian Universitas Sebelas Maret Surakarta \\ Contact Author: supriyadi_uns@yahoo.com
}

\begin{abstract}
Research purposes to determine the response of soybean varieties Kaba under protected forest tree stands besides soybean crop response to $P$ fertilizer and manure fertilizer micro coupled with organic fertilizer uptake and utilization of $P$ element to the low light under protected forest tree stands. The research was conducted in JulyDecember 2011. Experiments using Randomized Complete (RAKL) factorial consists of 3 factors, namely fertilization with manure $P 1$, factor 2 micro fertilization with manure, and a factor of 3 fertilizing with organic fertilizers. Each treatment combination was repeated 3 kali.Faktor first fertilizer $P$ fertilizer $P$ The first factor consists of three levels, namely P1 (50 kg/ha), P2 (75 kg/ha), and P3 (100 kg/ha). The second factor consists of 2 fertilizer micro level, ie $M 1(0.5 \mathrm{l} / \mathrm{ha})$ and $M 2(1.5 \mathrm{l} / \mathrm{ha})$. The third factor of organic fertilizer consisting of 2 levels, ie OO (0 tonnes / ha) and O1 (5 tonnes / ha). Data analysis using the F test level of 5\% followed by comparison test (DMRT) level of 5\%. The results show the interaction between $P$ fertilizer, micro fertilizer and organic fertilizer effect on soil $\mathrm{pH}, \mathrm{P}$ uptake, and the number of pods. $P$ fertilizer on fertilizer and organic fertilizer micro effects and no significant effect on available $P$ and heavy pod soybeans (Glycine max L.).
\end{abstract}

Keywords: P fertilizers, micro fertilizers, organic fertilizers and soy

\section{PENDAHULUAN}

Kedelai (Glycine max L) merupakan salah satu komoditas pangan strategis di Indonesia. Kedelai membutuhkan unsur P pada setiap masa pertumbuhannya (Supadi, 2008). Peningkatan produktivitas antara lain dilakukan dengan menggunakan benih varietas unggul bermutu, pengamanan produksi dengan memberikan bantuan sarana pascapanen, dan perbaikan sistem kelembagaan dengan memperbaiki sistem lembaga permodalan dan menguatkan peran gabungan kelompok tani dan kemitraan (Alimoeso, 2006).

Inseptisol berasal dari kata inceptium (permulaan) dan soil (tanah) adalah tanah yang dapat memiliki epipedon okhrik dan horizon albik, tanah ini masih muda, masih dalam tahap awal perkembangan. Satu atau lebih horison pedogenik dengan sedikit akumulasi bahan selain karbonat atau silikat amorf, tekstur lebih halus dari pasir geluhan dengan beberapa mineral lapuk dan kemampuan manahan kation fraksi lempung ke dalam tanah tidak dapat di ukur. Tanah inseptisol mempunyai karakteristik dari kombinasi sifat-sifat tersedianya air bagi tanaman lebih dari setengah tahun atau lebih dari 3 bulan berturut-turut dalam musim kemarau.

Pengaruh bahan organik terhadap ketersediaan $\mathrm{P}$ dapat secara langsung 
melaui proses mineralisasi atau secara tidak langsung dengan membantu pelepasan $\mathrm{P}$ yang terfiksasi. Ketersediaan $\mathrm{P}$ di dalam tanah dapat ditingkatkan dengan penambahan bahan organik melalui 5 aksi yaitu: (1) Melalui proses mineralisasi bahan organik terjadi pelepasan $\mathrm{P}$ mineral $\left(\mathrm{PO}_{4}{ }^{3-}\right)$; (2) Melalui aksi dari asam organik atau senyawa pengkelat yang lain hasil dekomposisi, terjadi pelepasan fosfat yang berikatan dengan $\mathrm{Al}$ dan $\mathrm{Fe}$ yang tidak larut menjadi bentuk terlarut. (3) Bahan organik akan mengurangi jerapan fosfat karena asam humat dan asam fulvat berfungsi melindungi sesquioksida dengan memblokir situs pertukaran; (4). Penambahan bahan organik mampu mengaktifkan proses penguraian bahan organik asli tanah; (5). Membentuk kompleks fosfo-humat dan fosfo-fulvat yang dapat ditukar dan lebih tersedia bagi tanaman, sebab fosfat dijerap oleh bahan organik secara lemah (Stevenson, 1982).

Unsur-unsur hara mikro merupakan unsur hara yang sama pentingnya dengan unsur-unsur hara hara makro bagi tanaman, walaupun dalam hal ini kebutuhannya hanya sedikit. Unsur hara mikro ini terdapat dari sumber dari batuan mineral, air irigasi dan sisa-sisa bahan organik. Pada umumnya hanya dibutuhkan sedikit sekali bagi tanaman dan unsur ini juga merupakan zat katalisator atau zat yang dapat mempercepat persenyawaan kimiawi didalam tubuh tanaman.

\section{BAHAN DAN METODE}

Penelitian ini dilaksanakan pada bulan Juli - Desember 2011, penanaman kedelai dilaksanakan di kawasan hutan lindung Gunung Gajah Klaten sedangkan untuk analisis laboratorium dilakukan di Laboratorium Kimia dan Kesuburan Tanah Fakultas Pertanian Universitas Sebelas Maret Surakarta.

Bahan yang dibutuhkan meliputi Benih kedelai varietas Kaba, Pupuk organik (Pupuk kandang kotoran sapi), Pupuk SP-36, Pupuk mikro dan Kemikalia untuk analisis laboratorium. Alat yang dibutuhkan meliputi Bor tanah, Belati, Alat tulis dan meteran, Timbangan, Oven, Plastik, Alat-alat untuk analisis laboratorium, Alat penanganan pasca panen, kamera digital untuk dokumentasi.

Penelitian dibagi menjadi 3 blok dengan 12 petak setiap bloknya sesuai jumlah perlakuan, dengan pembatas berupa pematang dengan konstruksi baik. Masing-masing petak luas sekitar $(1,4 \mathrm{~m} \mathrm{x} 1,2 \mathrm{~m})$ saluran air masuk dirancang terisolasi antar petak perlakuan, dibuat sepanjang blok dan air masuk ke petak perlakuan melalui pintu masing-masing, sehingga diperoleh 36 kombinasi perlakuan.

Pemberian pupuk organik
dilakukan sesuai
selang pada setiap petaknya atau dengan dosis 0 ton/Ha dan 5 ton/Ha, sedangkan untuk pemberian pupuk SP-36 diberikan secara merata setelah dilakukan tanah, dan untuk dosis yang digunakan yaitu sesuai perlakuan yang sudah ditentukan $50 \mathrm{~kg} / \mathrm{Ha}, \quad 75 \mathrm{~kg} / \mathrm{Ha}, \quad 100 \mathrm{~kg} / \mathrm{Ha}$. Sedangkan untuk pemberian pupuk mikro diberikan dengan cara dilarutkan dalam 10 liter aquadest, sesuai dengan dosis masing-masing dengan perlakuan yaitu 0,5 1/ha dan 1,5 1/Ha kemudian disemprotkan ke daun sebanyak 1 liter setiap petaknya, penyemprotan dilakukan pada pagi hari. Hal ini dikarenakan pada 
waktu pagi hari biasanya matahari belum begitu terik dan panas sehingga pupuk mikro tidak cepat menguap dan dapat diresap daun dengan maksimal.

Untuk analisis data dengan menggunakan uji $\mathrm{F}$ taraf 5\% (untuk data normal) dan uji Kruskal wallis (untuk data tidak normal), untuk mengetahui pengaruh perlakuan terhadap variabel pengamatan dilanjutkan dengan membedakan di antara perlakuan menggunakan DMRT taraf $5 \%$ dan untuk mengetahui perlakuan yang paling berpengaruh menggunakan uji stepwise regression. Uji korelasi untuk mengetahui hubungan keeratan antar variabel/hubungan antar perlakuan.

\section{HASIL DAN PEMBAHASAN}

\section{Pengaruh Perlakuan Terhadap Variabel Tanah}

Perbedaan pada $\mathrm{pH}$ tanah ini dikarenakan oleh pemberian dosis pupuk yang berbeda. Salisbury dan Ross (1995) menyatakan bahwa kelarutan unsur tertentu dan laju penyerapannya oleh tumbuhan sangat dipengaruhi oleh $\mathrm{pH}$, Besi, Seng, Tembaga, dan Mangan kurang larut pada tanah basa dibandingkan tanah asam karena ion ini mengendap sebagai hidroksida pada $\mathrm{pH}$ tinggi. Kemasaman tanah merupakan salah satu sifat yang penting, karena terdapat beberapa hubungan $\mathrm{pH}$ tanah dengan ketersediaan unsur hara, juga terdapat beberapa hubungan antara $\mathrm{pH}$ dan semua serat sifat-sifat tanah. Dari keterangan diatas dapat dilihat pada gambar dibawah ini.

Perbedaan $\mathrm{P}$ tersedia pada ketiga dosis pupuk $\mathrm{P}$ disebabkan karena pupuk P-alam mempunyai kelarutan yang rendah bila digunakan pada tanah yang bereaksi agak netral sampai netral, sehingga penyediaan hara $\mathrm{P}$ dari pupuk lebih lambat dibandingkan kebutuhan $\mathrm{P}$ untuk tanaman tersebut. Kualitas pupuk P-alam dipengaruhi oleh beberapa faktor yaitu: sifat mineral, kelarutan, besar butir, kadar karbonat bebas, kadar $\mathrm{P}_{2} \mathrm{O}_{5}$ total dan jenis deposit batuan fosfat. Efektivitas penggunaan P-alam sangat ditentukan oleh reaktivitas kimia, ukuran butir, sifat-sifat tanah, waktu dan cara aplikasi, takaran P-alam, jenis tanaman dan pola tanam (Lehr dan McClellan, 1972; Chien, 1995; Rajan et al., 1996).

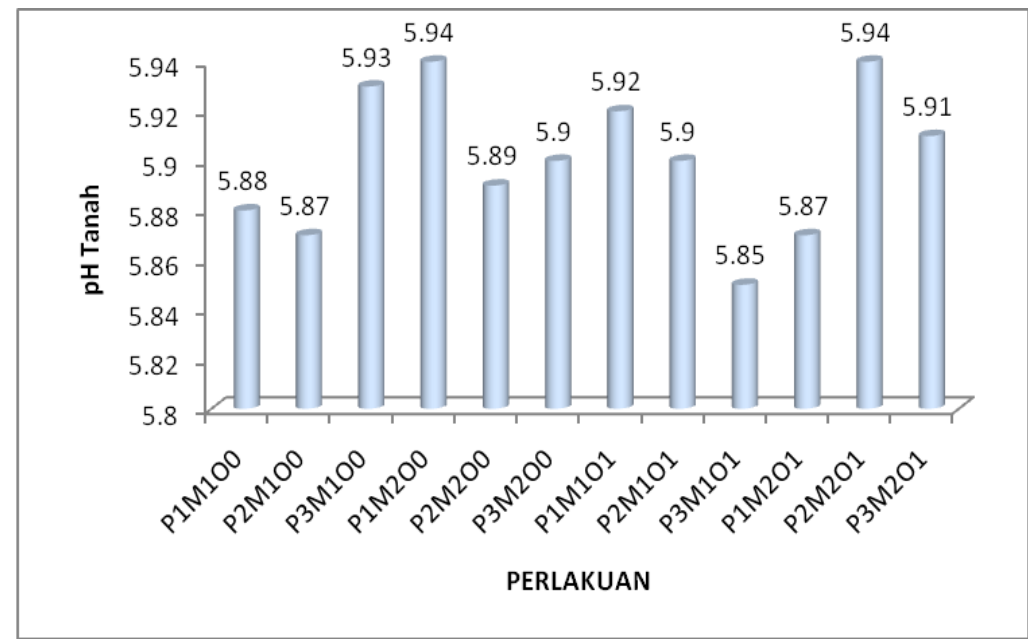

Gambar 1. Interaksi pupuk P, pupuk mikro dan pupuk organik terhadap $\mathrm{pH}$ tanah pada tanaman kedelai. 


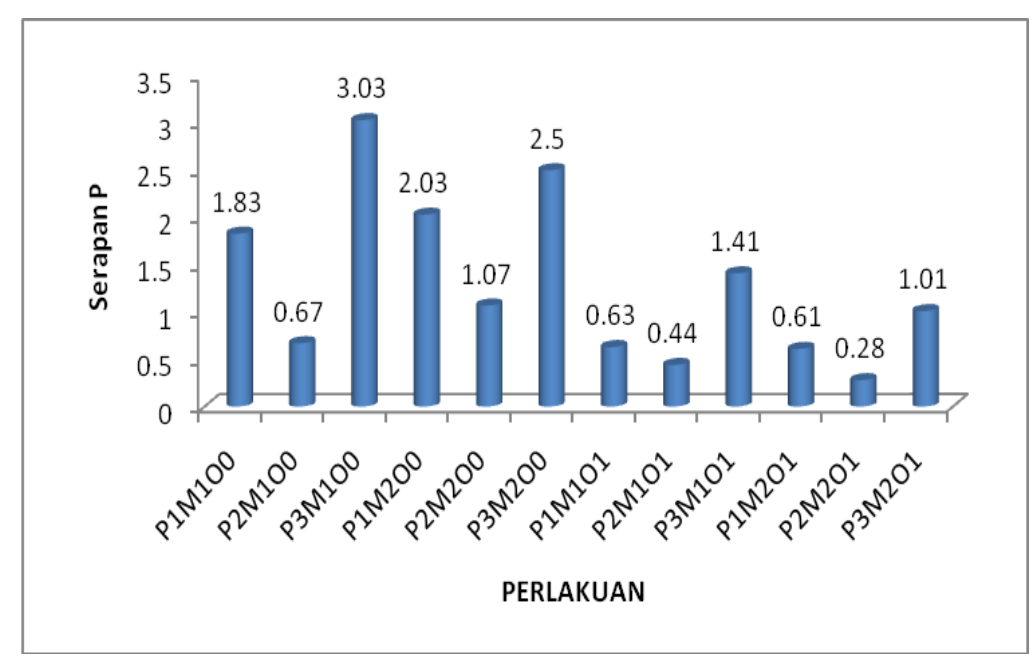

Gambar 2. Interaksi pupuk P, pupuk mikro dan pupuk organik terhadap serapan $\mathrm{P}$ pada tanaman kedelai.

\section{Pengaruh Perlakuan Terhadap Variabel Tanaman (Serapan P)}

Serapan hara pada hakekatnya adalah jumlah hara yang masuk ke dalam jaringan tanaman. Serapan hara diperoleh dari perkalian antara kadar hara dengan berat kering brangkasan (Yuwono, 2004). Serapan hara P pada masa vegetatif lebih besar dari masa generatif, karena pada masa generatif, tanaman kedelai membutuhkan hara $\mathrm{P}$ yang tinggi untuk pembentukan biji dan pengisian biji.

Dari keterangan Gambar 2 hasil analisis ragam yang diperoleh menunjukkan bahwa interaksi antara pupuk $\mathrm{P}$, pupuk mikro dan organik memberikan pengaruh yang nyata terhadap serapan $\mathrm{P}$ tanaman. Tanaman kedelai memerlukan serapan hara $\mathrm{P}$ yang tinggi pada masa generatif, karena pada masa ini hara $\mathrm{P}$ diimobilisasi menuju bagian-bagian generatif tanaman seperti polong tanaman yang sedang dalam proses pengisian biji. Besarnya serapan $\mathrm{P}$ tanaman tergantung dari ketersediaan unsur $\mathrm{P}$ dalam larutan tanah dan perakaran tanaman (Basir-Cyio, 2004).

\section{Pengaruh Perlakuan Terhadap Hasil Tanaman Kedelai}

Berat polong yang tinggi pada hasil diatas didukung juga oleh efisiensi serapan $\mathrm{P}$ serta pengaplikasian dari penggunaan pupuk $\mathrm{P}$ yang tinggi. Pemupukan fosfat menyebabkan meningkatnya ketersediaan $\mathrm{P}$ dalam tanah sehingga dapat memenuhi kebutuhan $\mathrm{P}$ untuk pertumbuhan dan produksi. Fosfor merupakan hara yang sangat dibutuhkan kedelai untuk pertumbuhan biji, sehingga suplai $\mathrm{P}$ yang cukup menyebabkan diperolehnya produksi yang memuaskan (Djafar, 1984 dalam_Brotonegoro et al., 1993). Seperti dijelaskan Ohlrogge dan Kamprath, (1968) bahwa pada tanaman kedelai retribusi hara sangat penting pada periode pengisian biji. Sejumlah nitrogen dan potassium dalam benih dialirkan dari jaringan vegetative matang ke jaringan reproduktif. Penyerapan fosfor maksimum terjadi pada saat pengisian biji (Effendi, 1980).

Gambar 3 dari hasil analisis akhir jumlah polong didapatkan hasil dari berbagai perlakuan pupuk yang diuji cobakan menunjukkan hasil yang 
Kajian Pemberian Pupuk P, Pupuk Mikro dan Pupuk Organik ... Supriyadi et. al

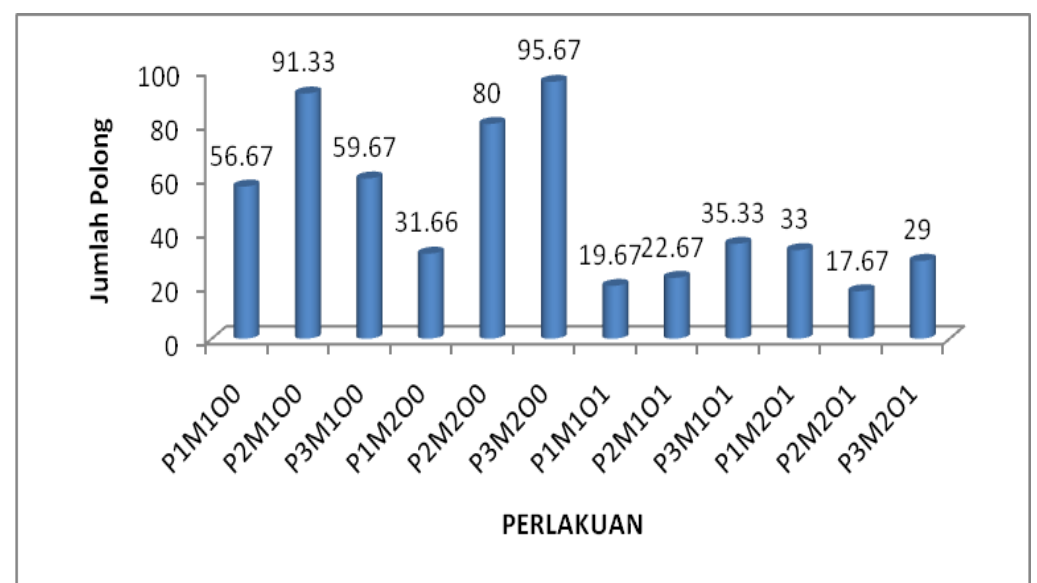

Gambar 3. Interaksi pupuk P, pupuk mikro dan pupuk organik terhadap jumlah polong pada tanamankedelai.

signifikan yaitu memberikan pengaruh yang tidak nyata terhadap jumlah polong. Perbedaan jumlah polong pada hasil kedelai ini disebabkan perbedaan laju proses fotosintesis selama fase reproduktif, yang kurang maksimal. Pertumbuhan bagian atas yang baik akan menunjang proses fotosintesis selama periode pengisian biji. Unsur $\mathrm{K}$ sangat berperan dalam proses pembentukan polong dan polong bernas pada tanaman kedelai. Semakin tinggi K maka pembentukan dan pengisian polong semakin berjalan sempurna (Hanibal, et al., 1995).

\section{KESIMPULAN}

Interaksi antara pupuk $\mathrm{P}$, pupuk mikro dan pupuk organik maupun interaksinya pada tanaman kedelai (Glycine $\max$ L.) berpengaruh sangat nyata terhadap $\mathrm{pH}$ tanah, serapan $\mathrm{P}$ dan jumlah polong. Untuk pemberian antara pupuk P, pupuk mikro dan pupuk organik pada tanaman kedelai (Glycine $\max L$ ) memberikan pengaruh yang tidak nyata terhadap $\mathrm{P}$ tersedia dan berat polong pada tanaman. Pada rata-rata $\mathrm{P}$ tersedia tertinggi dicapai pada perlakuan P3M2O0 dengan 12,270 ppm dan $P$ tersedia paling rendah pada perlakuan P2M1O1 dengan 6,302 ppm. Pada serapan $\mathrm{P}$ tertinggi dicapai oleh perlakuan P3M1O0 dengan 3,034 $\mathrm{mg} /$ tanaman dan untuk serapan $\mathrm{P}$ paling rendah yaitu pada perlakuan P2M2O1 dengan $0,375 \mathrm{mg} /$ tanaman.

\section{SARAN}

Berdasarkan pembahasan diatas perlu sekali dilakukan penelitian yang lebih lanjut untuk menentukan dosis pemupukan pupuk $\mathrm{P}$, pupuk mikro dan pupuk organik yang tepat guna meningkatkan hasil kedelai (Glycine max L.) yang maksimal dilokasi penelitian.

\section{DAFTAR PUSTAKA}

Alimoeso, S. 2006. Tahun 2006, Deptan RI Canangkan Program Bangkit Kedelai. Dalam www.jabar.go.id, 1 Juni 2010.

Basir-Cyio, M., 2004. Aplikasi indeks biokimia dalam penentuan karakteristik dan kesuburan tanah yang diberi bahan organik terinkubasi. J. Agroland Vol. 11 (1) : 65-72.

Djafar, B. 1982. Substitusi Pupuk KCl dengan Limbah Kelapa Sawit Untuk Tanaman Cengkeh dan Kedelai. Jurnal Agrotropika Volume IV (2): 78: 15-17. Bogor. 
Kajian Pemberian Pupuk P, Pupuk Mikro dan Pupuk Organik ... Supriyadi et. al

Hanibal, Sarman, Gusniwati. 2001.

Pemanfaatan Abu Janjang Kelapa Sawit Pada Lahan Kering dan Pengaruhnya Terhadap Pembentukan Nodula Akar, Pertumbuhan dan Hasil Tanaman Kedelai (Glaycine max). Fakultas Pertanian. Universitas Jambi. Jambi.

Ohlrogge, A. J and Kamprath E.J. 1968. Fertilizers Use in Soybeans. IN Nelson, L. B. Eds. Changing Patterns in Fertilizer Use. Soil Sci. Soc.of Am. Inc. Madison, Wisconsin, USA.
Salisbury, F. B dan C. W. Ross. 1995. Fisiologi Tumbuhan Jilid 2. Perkembangan Tumbuhan dan Fisiologi Lingkungan. Penerjemah; Diah R. Lukman dan Sumaryono. Terjemahan dari: Plant Physiology. Institut Teknologi Bandung Press. 342 hal.

Stevenson, F.T. 1982. Humus Chemistry. John Wiley and Sons. Newyork.

Supadi, 2008. Menggalang Partisipasi Petani Untuk Meningkatkan Produksi Kedelai Menuju Swasembada. Jurnal Litbang Pertanian, 27(3), 2008107.

Yuwono D. 2004. Kompos. Jakarta: Penebar Swadaya. 